\title{
Endothelial Cell-mediated Conversion of Glu-Plasminogen to Lys-Plasminogen Further Evidence for Assembly of the Fibrinolytic System on the Endothelial Cell Surface
}

\author{
Katherine A. Hajjar* and Ralph L. Nachman \\ Divisions of Hematology-Oncology, Departments of Pediatrics* and Medicine, and Specialized Center of Research in Thrombosis, \\ Cornell University Medical College, New York 10021
}

\begin{abstract}
Lysine-plasminogen (Lys-PLG), the plasmin-modified form of native glutamic acid-plasminogen (Glu-PLG), displays enhanced binding affinity for fibrin and also enhanced activation by urokinase and tissue plasminogen activator. We previously demonstrated high-affinity, specific, and functional binding of Glu-PLG as well as tissue plasminogen activator to cultured human umbilical vein endothelial cells (HUVEC). In the present study, we demonstrate binding of Lys-PLG to HUVEC, as well as conversion of Glu-PLG to Lys-PLG at the cell surface. Binding of Lys-PLG to HUVEC was saturable, reversible, $\epsilon$-aminocaproic acid-sensitive, and involved two saturable sites with $K_{d}$ 's of $142 \mathrm{pM}$ and $120 \mathrm{nM}$, respectively. Upon incubation with Glu-PLG, HUVEC, as well as endothelium in situ, partially converted the ligand to a Lys-PLG-like species. Conversion by HUVEC was blocked by diisopropylfluorophosphate, but not by other serine protease inhibitors, including $\alpha_{\mathbf{2}}$-plasmin inhibitor. Eluates of intact umbilical cord vessels contained Lys-PLG by immunoblot analysis. Lys-PLG was also identified immunohistochemically on the endothelial surface of vessels from a variety of normal and inflamed tissues. Thus, endothelial cells appear to actively modify circulating Glu-PLG, bind Lys-PLG to their surface, and thus enhance the fibrinolytic potential of the blood vessel wall.
\end{abstract}

\section{Introduction}

Lysine-plasminogen (Lys-PLG) ${ }^{1}$ is the $85,000-\mathrm{kD}$ plasminmodified form of native, circulating glutamic acid-plasminogen (Glu-PLG). Plasmin cleaves the Lys 76-Lys 77 bond resulting in the release of a 76-amino acid "preactivation peptide" and formation of Lys-PLG (1-3). Although it does not circulate in the plasma (4), Lys-PLG displays enhanced binding affinity for fibrin (5), and is activated more readily than Glu-PLG by both tissue plasminogen activator (6) and uroki-

A preliminary report of these data was presented at the annual meeting of the American Society of Hematology in 1987.

Address reprint requests to Dr. Hajjar.

Received for publication 5 February 1988 and in revised form 12 May 1988.

1. Abbreviations used in this paper: $\alpha_{2}$-PI, $\alpha_{2}$-plasmin inhibitor; DFP, diisopropylfluorophosphate; EACA, $\epsilon$-aminocaproic acid; Glu-PLG, $N$-terminal glutamic acid plasminogen; HUVEC, human umbilical vein endothelial cells; Lys-PLG, $N$-terminal lysine plasminogen; PAI, plasminogen activator inhibitor; PPACK, D-phenylalanyl-L-prolyl-Larginine chloromethylketone.

J. Clin. Invest.

(c) The American Society for Clinical Investigation, Inc.

$0021-9738 / 88 / 11 / 1769 / 10 \$ 2.00$

Volume 82, November 1988, 1769-1778 nase $(7,8)$. In the presence of tissue plasminogen activator, Lys-PLG is activated with 10 to 20 times greater catalytic efficiency $\left(k_{\text {cat }} / K_{\mathrm{m}}\right)$ than Glu-PLG (6). This increase in activatability reflects a decrease in the $K_{\mathrm{m}}$ of the reaction with little corresponding change in the catalytic rate constant $\left(k_{\text {cat }}\right)(6)$.

We have previously demonstrated that native Glu-PLG (9), and its activators (10), bind with high specificity and affinity to the surface of cultured human umbilical vein endothelial cells (HUVEC). Binding of Glu-PLG, which was dose dependent, saturable, reversible, and lysine binding site dependent, resulted in a 12-fold increase in zymogen activatability on the cell surface due to a log-order decrease in the $K_{\mathrm{m}}$ of the activation reaction (9). We therefore examined whether this increase in catalytic efficiency at the endothelial cell surface might reflect the formation of a more efficiently activated plasminogen species.

In this report we demonstrate dose-dependent, and lysinebinding site-dependent interaction of authentic Lys-PLG to two saturable binding sites on cultured HUVEC. Unlabeled Lys-PLG was a more effective competitor of ${ }^{125}$ I-Lys-PLG binding than unlabeled Glu-PLG, whereas either one competed effectively with ${ }^{125} \mathrm{I}-\mathrm{Glu}-\mathrm{PLG}$ for cell surface binding sites. Upon association with cultured HUVEC or endothelial cells in situ, ${ }^{125} \mathrm{I}-\mathrm{Glu}-\mathrm{PLG}$ was partially converted to a species which comigrated with ${ }^{125}$ I-Lys-PLG, through a reaction which was completely inhibited by the serine protease inhibitor diisopropylfluorophosphate (DFP). Lys-PLG cross-reactive material was also detected by immunoblot analysis of eluates of intact umbilical cord veins, and by immunohistochemical staining of vascular endothelium in a variety of tissues. Therefore, Lys-PLG may represent a form unique to the cell surface, and endothelial cell-mediated conversion of GluPLG to Lys-PLG may contribute to the nonthrombogenic nature of the endothelium.

\section{Methods}

Materials. 96- (Falcon Labware, Oxnard, CA) and 24- (Costar, Cambridge, MA) well tissue culture plates were employed. L-Glutamine, penicillin-streptomycin, fungizone, porcine intestinal mucosal heparin, BSA (essentially fatty acid- and globulin-free), lactoperoxidase, tissue culture grade EDTA, DFP, phenylmethylsulfonyl fluoride, leupeptin, and $p$-nitrophenylphosphate were from Sigma Chemical Co., St. Louis, MO. Iodoacetic acid was purchased from Eastman Organic Chemicals, Rochester, NY; pancreatic trypsin inhibitor from Cooper Biomedical, Inc., Malvern, PA; and D-phenylalanyl-L-prolyl-L-arginine chloromethylketone (PPACK) from Calbiochem-Behring Corp., La Jolla, CA. Collagenase (type I) was obtained from Worthington Diagnostics, Bedford, MA. Immobilon (polyvinylidene difluoride) transfer membranes were purchased from Millipore Corp., Bedford, MA. $P$-Nitroblue tetrazolium chloride and 5-bromo-4-chloro-3indolylphosphate $p$-toluidine were obtained from Bio-Rad Laboratories, Richmond, CA.

Purified proteins. Authentic human Glu-PLG, form 1 was kindly provided by Dr. Francis J. Castellino, University of Notre Dame, 
Notre Dame, IN, and authentic human Lys-PLG by Dr. J. Eibl, Immuno, Vienna, Austria. In most experiments, these proteins were treated with DFP before use to inactivate any contaminating plasmin. Human Glu-PLG was also purchased from IMCO, Stockholm, Sweden. All preparations were tested for plasmin activity using a fluorometric assay as previously described (9). $\alpha_{2}$-plasmin inhibitor $\left(\alpha_{2}\right.$-PI) was kindly provided by Dr. Peter Harpel, Cornell University Medical College, New York. "Working standard" plasminogen activator inhibitor (PAI), type I was provided by Dr. Patrick Gaffney, National Institute for Biological Standards and Controls, Hertfordshire, England.

Antibodies. Monoclonal antibody to Lys-PLG (LPm1) was generously provided by Dr. Paul Holvoet, Katholieke Universiteit, Leuven, Belgium. The specificity and characterization of this antibody have been previously described (4). Monoclonal antibody to human plasminogen (3641) reactive with both Lys-PLG and Glu-PLG was purchased from American Diagnostica, New York. Monoclonal antihuman light chain was purchased from Dako Corp., Santa Barbara, CA. Monoclonal anti-human albumin was purchased from Chemicon International, El Segunda, CA. Mouse monoclonal antibody to human prothrombin was obtained from Cappel Biochemicals, Malvern, PA. Alkaline phosphatase-conjugated polyclonal antibody to human plasminogen was kindly provided by Dr. Peter Harpel.

Cell culture. HUVEC were cultured and quantified as previously described $(9,10)$. Where indicated, HUVEC were grown in plasminogen-depleted medium $(<1 \%)$.

Cell monolayer ELISAs. Cell monolayer ELISAs were carried out as previously described $(9,10)$ utilizing alkaline phosphatase-conjugated polyclonal rabbit antibody directed against human plasminogen in a one-step detection system.

Radioisotope labeling and radioligand binding studies. Purified human Glu-PLG and Lys-PLG were radiolabeled by the lactoperoxidase method (11) as previously described (9). Radioligand binding studies with ${ }^{125}$ I-Lys-PLG were carried exactly as described for ${ }^{125} \mathrm{I}$ Glu-PLG (9), and analyzed according to the LIGAND computer program (12).

$S D S-P A G E$. Samples were dissolved in $5 \%$ SDS, $50 \mathrm{mM}$ Tris, 5 mM EDTA, 25\% sucrose (wt/vol), and $50 \mu \mathrm{g} / \mathrm{ml}$ bromphenol blue. Samples were applied to $7.5 \%$ or $9.0 \%$ Laemmli (13) slab gels $(3.9 \%$ stacking gels), and electrophoresed under nonreducing conditions overnight with cooling at constant power. Gels for autoradiography were fixed in $10 \%$ methanol/7\% acetic acid, dried, and autoradiographed. In some experiments, autoradiograms were scanned using a Model 2202 Ultroscan laser densitometer (LKB Instruments, Inc., Gaithersburg, MD).

Immunoblotting. Protein bands in SDS-polyacrylamide gels were electrophoretically blotted onto transfer membranes in a tank system using a buffer containing $25 \mathrm{mM}$ Tris, $190 \mathrm{mM}$ glycine, and $20 \%$ (vol/vol) methanol for $90 \mathrm{~min}, 800 \mathrm{~mA}, 21^{\circ} \mathrm{C}(14,15)$. Nontransferred strips from the same gel were stained in Coomassie Blue $(0.1 \%$ [wt/vol] in 50\% methanol/10\% acetic acid) and destained in $10 \%$ methanol/7\% acetic acid. The membranes were then incubated with blocking buffer consisting of TBS (Tris-buffered saline: $150 \mathrm{mM} \mathrm{NaCl}, 20 \mathrm{mM}$ Tris, pH 7.4) containing $50 \mathrm{mg} / \mathrm{ml} \mathrm{BSA}, 60 \mathrm{~min}, 37^{\circ} \mathrm{C}$. The membranes were washed three times in TBS containing $1 \mathrm{mg} / \mathrm{ml} \mathrm{BSA}$, and incubated either with alkaline phosphatase-conjugated rabbit anti-human plasminogen at a $1: 1,000$ dilution in TBS containing $10 \mathrm{mg} / \mathrm{ml} \mathrm{BSA}$, $60 \mathrm{~min}, 21^{\circ} \mathrm{C}$ or with mouse monoclonal anti-Lys-PLG $(1: 500,60$ min, $21^{\circ} \mathrm{C}$ ), followed by three washes and incubation with goat antimouse immunoglobulin $\left(1: 500,60 \mathrm{~min}, 21^{\circ} \mathrm{C}\right)$ in the same buffer system. Finally, the membranes were washed again three times as described, and developed in carbonate buffer (100 mM NaHCO $\mathrm{mM} \mathrm{MgCl} 2, \mathrm{pH} 9.8)$ containing $p$-nitroblue tetrazolium chloride (180 $\mu \mathrm{g} / \mathrm{ml})$ and 5-bromo-4-chloro-3-indolylphosphate $p$-toluidine (90 $\mu \mathrm{g} / \mathrm{ml}), 5-10 \mathrm{~min}, 21^{\circ} \mathrm{C}(16)$.

Immunohistology. Fresh tissue was snap frozen in optimum cutting temperature medium (Miles Laboratories, Naperville, IL). 5- $\mu \mathrm{m} \mathrm{sec-}$ tions were made on a cryostat, mounted on gelatinized glass slides, and stained using an avidin-biotin complex immunoperoxidase kit (Vector Laboratories, Burlingame, CA). The sections were counterstained with hematoxylin.

\section{Results}

Binding of Lys-PLG to HUVEC. Upon exposure of HUVEC to authentic Lys-PLG or Glu-PLG, binding occurred in a dose-dependent and apparently saturable fashion (Fig. 1). As previously described (9), Glu-PLG binding to HUVEC was half-maximal at an input concentration of $\sim 0.54 \mu \mathrm{M}$ and approached saturation at concentrations of 1.5-2.5 $\mu \mathrm{M}$. LysPLG, on the other hand, although approaching saturation in the same concentration range, achieved half-maximal binding at an input dose of $\sim 0.27 \mu \mathrm{M}$, suggesting at least a twofold higher-affinity interaction as compared with Glu-PLG. As apparent saturation was approached, the rate of change in absorbance $(\triangle A 405 \mathrm{~nm})$ in this assay increased several times more rapidly for Lys-PLG than for Glu-PLG. This observation most likely reflected more efficient detection of cell surface LysPLG by this polyclonal antibody, since, as noted below (see Fig. 3 and text), binding sites for Glu-PLG were two to three times more prevalent than binding sites for Lys-PLG.

As demonstrated in Fig. 2, Lys-PLG bound rapidly to cultured HUVEC, reaching a steady state at 20-30 min. Binding

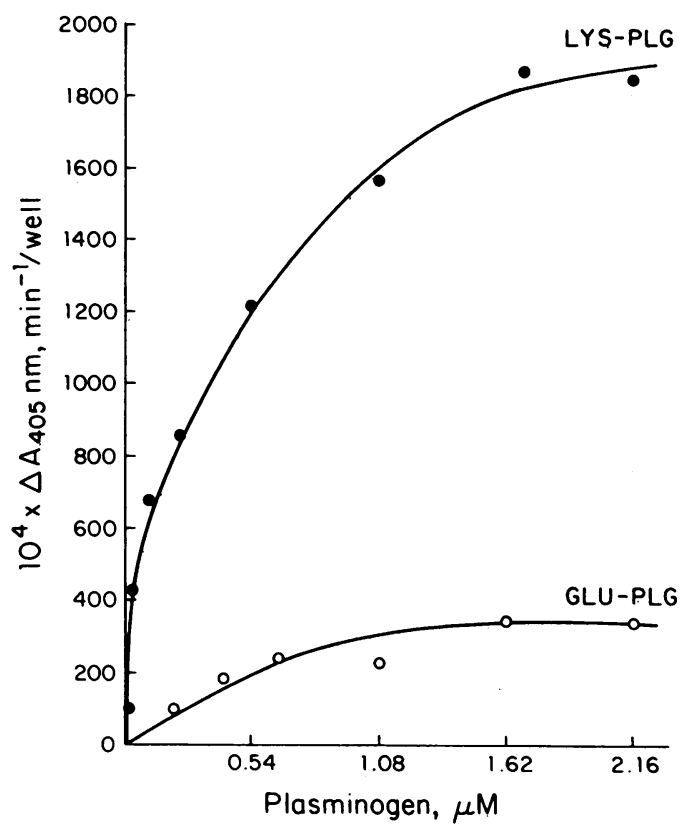

Figure 1. Interaction of Glu-PLG and Lys-PLG with HUVEC. HUVEC were grown to confluency in plasminogen depleted medium in 96-well plates, equilibrated to $4^{\circ} \mathrm{C}$, and washed three times in IB(2) (11 mM Hepes, $137 \mathrm{mM} \mathrm{NaCl}, 4 \mathrm{mM} \mathrm{KCl}, 3 \mathrm{mM} \mathrm{CaCl}_{2}, 1$ $\mathrm{mM} \mathrm{MgCl}, 11 \mathrm{mM}$ glucose, $2 \mathrm{mg} / \mathrm{ml} \mathrm{BSA}$ ). HUVEC were then incubated for $30 \mathrm{~min}$ with various concentrations ( $24 \mathrm{nM}$ to $2.2 \mu \mathrm{M}$ in IB[2]) of purified human Glu-PLG (0) or Lys-PLG (๑). The monolayers were washed three times with $\operatorname{IB}(2)$, and fixed with $0.02 \%$ glutaraldehyde. After three additional washes with PBS/Tween/BSA, rabbit anti-human plasminogen conjugated to alkaline phosphatase was added at a dilution of $1: 500$, and the plates incubated at $37^{\circ} \mathrm{C}, 3$ $h$. The monolayers were washed again, and binding estimated as a reflection of change in absorbance at $405 \mathrm{~nm}$ due to hydrolysis of the $p$ nitrophenylphosphate substrate. Average values for duplicate samples are shown. 


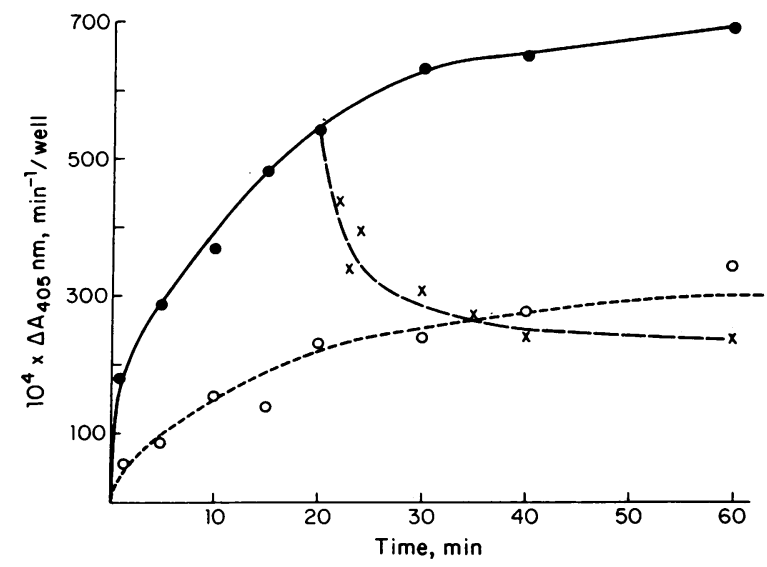

Figure 2. Time course and reversibility of Lys-PLG binding to HUVEC. HUVEC, prepared as described in Fig. 1, were incubated at $4^{\circ} \mathrm{C}$ with Lys-PLG, $100 \mu \mathrm{g} / \mathrm{ml} \mathrm{IB(2)( \bullet )} \mathrm{or} \mathrm{IB(2)} \mathrm{containing} 10 \mathrm{mM}$ EACA (0). At various time points (1-60 min), wells were emptied, washed five times rapidly (total wash time, $50 \mathrm{~s}$ ), and fixed with dilute glutaraldehyde. Parallel wells $(X)$ were washed five times and filled with $300 \mu \mathrm{l}$ of $\mathrm{IB}(2)$ starting at $20 \mathrm{~min}$ to approximate "infinite dilution" as previously described (9). These wells were subsequently washed three times and fixed at the indicated time points. Bound Lys-PLG was assayed at antibody dilution 1:1,000 as described in the legend to Fig. 1. Average values for duplicate samples are shown.

in the presence of $\epsilon$-aminocaproic acid (EACA) was significantly lower than in its absence, and represented $\sim 30 \%$ of total binding at the input concentrations tested. Thus, $\sim 70 \%$ of binding could be inhibited by this lysine analogue, indicating that this proportion of binding was lysine-binding site dependent. As binding approached a steady state, reversibility was demonstrated by "infinite dilution" of the unbound ligand at $20 \mathrm{~min}$. At this time point, $\sim 70 \%$ of total bound ligand dissociated over the next $40 \mathrm{~min}$. In addition, isotherms for Lys-PLG binding studies performed at $4^{\circ} \mathrm{C}$ and at $37^{\circ} \mathrm{C}$ over a 30-min incubation were superimposable, suggesting that little internalization of the ligand occurred over the time frame of this experiment (not shown).

In order to more precisely determine the binding affinity and capacity for the interaction of Lys-PLG with cultured HUVEC, radioligand studies were performed (Fig. 3). ${ }^{125} \mathrm{I}-$ Lys-PLG, in a manner similar to the unlabeled ligand, interacted with HUVEC in a dose-dependent manner (Fig. $3 A$ ). Binding approached saturation at total ligand concentrations of 1.7-2.4 $\mu \mathrm{M}$. Scatchard analysis of the data (Fig. $3 \mathrm{~B}$ ), indicated a two-site binding system $(P=0.003)$ consisting of both high- $\left(K_{d} 142 \mathrm{pM} ; B_{\max } 20,000\right.$ sites per cell) and low- $\left(K_{d} 120\right.$ $\mathrm{nM} ; B_{\max } 390,000$ sites per cell) affinity binding sites. Given the expected error for this type of measurement, the $K_{d}$ established for the lower-affinity binding site (124 $\mathrm{nM}$ ) was in good agreement with that estimated from ELISA experiments (270 nM) depicted in Fig. 1. When radiobinding studies were repeated with ${ }^{125}$ I-Glu-PLG as the ligand, a single saturable site with a $K_{\mathrm{d}}$ of $268 \mathrm{nM}$ and $B_{\max }$ of 854,000 sites per cell was found. These values agree reasonably well with those obtained previously (9), demonstrating that the binding properties of the cells employed have not changed substantially with respect to plasminogen binding.

To determine whether Glu-PLG and Lys-PLG might share a common binding site on the endothelial cell surface, we conducted "cold competition" experiments in which we compared inhibition of ${ }^{125}$ I-Lys-PLG binding to HUVEC by excess quantities of unlabeled Lys-PLG or unlabeled Glu-PLG (Fig. 4 A). $50 \%$ inhibition $\left(\mathrm{I}_{50}\right)$ of specific (EACA-inhibitable) ${ }^{125} \mathrm{I}$ Lys-PLG binding, was achieved at a molar ratio of unlabeled Lys-PLG to labeled Lys-PLG of $\sim 1: 1$. In addition, maximum inhibition $\left(98.8 \%\right.$ ) of specific ${ }^{125}$ I-Lys-PLG binding was achieved at 150-200-fold molar excesses of unlabeled ligand. In this experiment, nonspecific binding (that proportion not competed by excess cold Lys-PLG) was $26 \%$ of the total. This indicated that essentially all EACA-inhibitable binding could also be competed by "cold" ligand. In addition, since the $I_{50}$ for this competition represented a 1:1 molar ratio, labeled and unlabeled ligands have essentially equal affinity for Lys-PLG binding sites on the cell surface. When unlabeled Glu-PLG
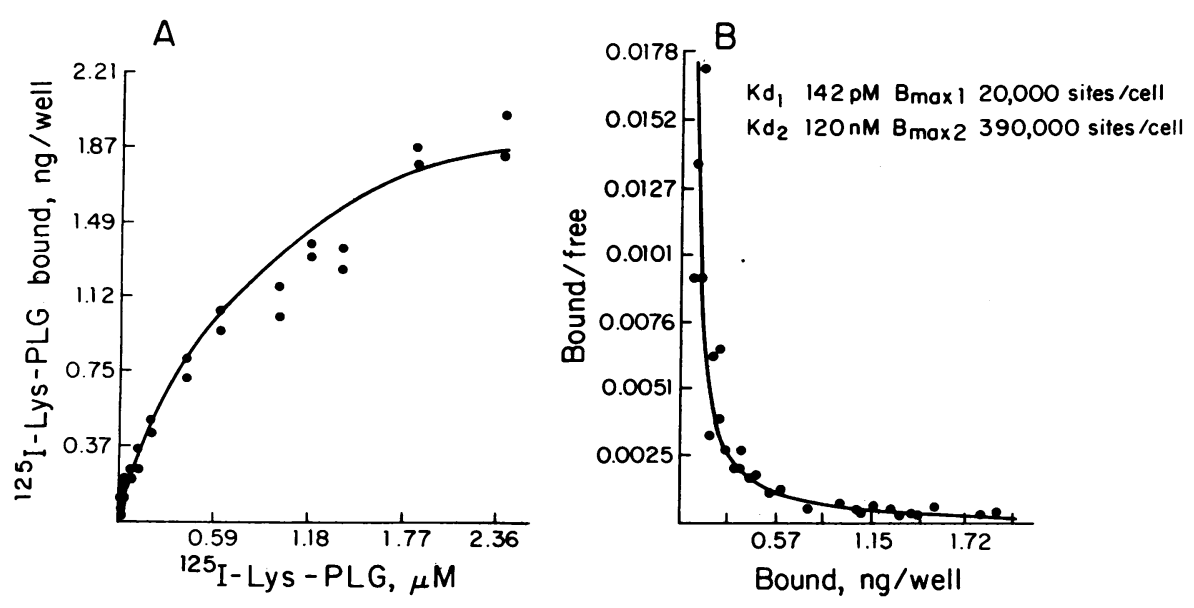

Figure 3. Binding of ${ }^{125} \mathrm{I}-\mathrm{Ly}$-PLG to HUVEC. $(A)$ Binding isotherm. HUVEC grown to confluency in 24-well plates in plasminogen-depleted medium were washed twice with IB(5) (11 mM Hepes, $137 \mathrm{mM} \mathrm{NaCl}, 4 \mathrm{mM} \mathrm{KCl}, 3 \mathrm{mM}$ $\mathrm{CaCl}_{2}, 1 \mathrm{mM} \mathrm{MgCl} 2,11 \mathrm{mM}$ glucose, 5 $\mathrm{mg} / \mathrm{ml} \mathrm{BSA}$ ). ${ }^{125}$ I-Lys-PLG (sp act 22,780 $\mathrm{cpm} / \mathrm{pmol}$ ), diluted in various ratios with unlabeled Lys-PLG, was added to duplicate wells $(450 \mu \mathrm{l} /$ well) and incubated, $4^{\circ} \mathrm{C}, 30 \mathrm{~min}$. Unbound radioactivity from a $100-\mu l$ aliquot was sampled before emptying and washing each well rapidly five times (total wash time $45 \mathrm{~s}$ ). Bound radioactivity was recovered in the washed cell fraction solubilized in $500 \mu \mathrm{l}$ of $1 \%$ $\mathrm{SDS} / 0.5 \mathrm{M} \mathrm{NaOH} / 0.01 \mathrm{M}$ EDTA, and counted as a $100-\mu l$ aliquot. (B) Scatchard plot. Data were analyzed according to the Ligand program of Munson and Rodbard (12). 


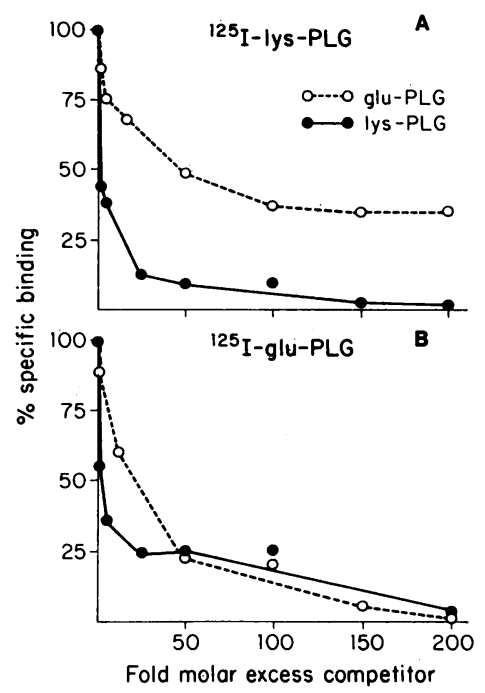

taining increasing molar excesses $(0-200)$ of un Lys-PLG. Bound ${ }^{125}$ I-Glu- or ${ }^{125}$ I-Lys-PLG was quantified as described in Fig. 3. Average values for duplicate samples are shown.

was used as the competing ligand, $50 \%$ inhibition of specific ${ }^{125}$ I-Lys-PLG binding was achieved at a molar ratio of $\sim 48: 1$ unlabeled Glu-PLG/labeled Lys-PLG. In addition, only $65 \%$ of specific ${ }^{125}$ I-Lys-PLG binding could be inhibited by a 100-200-fold molar excess of unlabeled Glu-PLG, suggesting that Glu-PLG represented a less effective competitor.

Fig. $4 B$ illustrates an analogous experiment in which unlabeled Glu-PLG and Lys-PLG were evaluated as competitors against ${ }^{125}$ I-Glu-PLG in its binding reaction with HUVEC. The two forms competed equally well for specific binding sites occupied by ${ }^{125}$ I-Glu-PLG. The competition curve for LysPLG in this experiment, moreover, shows an $\mathrm{I}_{50}$ of 1.5 -fold vs. 20-fold molar excess for Glu-PLG as previously reported (9), suggesting a higher affinity of the relevant binding site for Lys-PLG. These results suggest that Lys-PLG may be the preferred ligand for at least a proportion of plasminogen binding sites on HUVEC.

Endothelial cell surface-mediated conversion of Glu-PLG to Lys-PLG. When HUVEC in monolayer or suspension were incubated with authentic ${ }^{125}$ I-Glu-PLG, a new, more rapidly migrating molecular species of $\sim 87,000 \mathrm{kD}$ was detected by electrophoresis in 7.5 or $9.0 \%$ nonreducing SDS Laemmli gels followed by autoradiography (Fig. 5). In a previous study (9), we reported that ${ }^{125} \mathrm{I}-$ Glu-PLG, upon binding to HUVEC, was recoverable in a form which comigrated with the input material. However, the SDS-PAGE system employed in those earlier experiments (3.5-17\% Fairbanks system under reducing conditions) did not separate Glu- and Lys- forms. The new protein detected in the current study comigrated with authentic ${ }^{125}$ I-Lys-PLG (lanes 1, 3, and 4), and also reacted with a Lys-PLG-specific monoclonal antibody (LPm1) (4) in immunoblot analyses (not shown). It did not appear when ${ }^{125} \mathrm{I}-$ Glu-PLG was self-incubated (lane 2). The new band accounted for $38.6 \pm 2.2 \%$ (SD, $n=3$ ) of the recovered material by densitometry when the experiment was performed at $4^{\circ} \mathrm{C}$. At an incubation temperature of $21^{\circ} \mathrm{C}$, a larger proportion $(58.4 \pm 2.0 \%, \mathrm{SD}, n=3)$ of the labeled ligand was recovered as the lower molecular mass species, suggesting that appearance
Figure 5. Recovery of ${ }^{125}$ I-Glu-PLG from cultured HUVEC.

HUVEC, grown in 96well plates, were washed twice with IB(2) (see Fig. 1) and incubated with ${ }^{125}$ I-Glu-PLG, form 1 (sp act 266,000 $\mathrm{cpm} / \mathrm{pmol} ; 4.5 \mu \mathrm{g} / \mathrm{well})$, $30 \mathrm{~min}, 4^{\circ} \mathrm{C}$. The cells were then washed three times with $\mathrm{IB}(2)$, and either solubilized in $1 \%$ SDS/0.5 M NaOH/0.01 $M$ EDTA or surfaceeluted with $\mathrm{IB}(2) / 10$ mM EACA. Authentic ${ }^{125}$ I-Lys-PLG (lane 1), authentic self-incubated ${ }^{125}$ I-Glu-PLG (lane 2), whole cell extracts (lanes 3 and 4), and EACA eluates (lanes 5 and 6 ) were run on a $7.5 \%$ nonreducing Laemmli SDS polyacrylamide gel, fixed, dried, and exposed. A small amount of inactive plasmin was present in the authentic Glu-PLG sample (lane 2, lower band).

of the new band was relatively temperature dependent. In time course studies performed at $4^{\circ} \mathrm{C}$ or at $37^{\circ} \mathrm{C}$, the lower molecular mass species appeared within $10 \mathrm{~min}$, plateaued at $\sim 30$ min, and persisted for up to $4 \mathrm{~h}$ (data not shown). Neither empty wells, nor wells coated with postculture medium produced the same effect when incubated with the ligand, demonstrating that the reaction was not due to a soluble substance in the medium or contaminant on the well. Regardless of whether cells were studied in monolayer or in suspension, the appearance of a new $\sim 87,000-\mathrm{kD}$ species was consistently noted, thus ruling out a major contribution by subendothelial matrix, and implicating the cell surface. In addition, as shown in Fig. 5 (lanes 5 and 6 ), 95\% of both molecular species could be eluted from the HUVEC surface with incubation buffer containing $10 \mathrm{mM}$ EACA. This indicated that the bulk of the ligand was not internalized during the time frame of the experiment, and that the cell-ligand interaction was lysine-binding site dependent (Fig. 5).

To determine whether binding of Glu-PLG to endothelial cells in situ could also be associated with conversion to a LysPLG-like species, umbilical vein perfusion experiments were carried out (Fig. 6). Veins of intact, fresh umbilical cords were cannulated, washed to remove plasma proteins, and incubated with authentic ${ }^{125}$ I-Glu-PLG, form 1 . The eluates were then collected, and the vessels washed to remove residual protein. In a final step, the vessels were eluted with an EACA-containing buffer. Samples were run on SDS gels and autoradiographed. While the final wash material contained only Glu- 


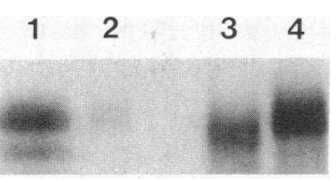

Figure 6. Recovery of ${ }^{125} \mathrm{I}-\mathrm{Glu}-\mathrm{PLG}$ from umbilical cord veins. The vein of a segment of fresh intact umbilical cord was rinsed with Hepes-buffered saline (HBS; $11 \mathrm{mM}$ Hepes, $137 \mathrm{mM}$ $\mathrm{NaCl}, 4 \mathrm{mM} \mathrm{KCl}, 11 \mathrm{mM}$ glucose) with $\sim 10 \mathrm{ml} / \mathrm{cm}$ cord length (eluant $A_{280}<0.005$ ). The vessel was filled with HBS containing ${ }^{125}$ I-Glu-PLG, form $1(169,500 \mathrm{cpm} /$ pmol; $31 \mathrm{nM}$ ), and incubated at $4^{\circ} \mathrm{C}, 30 \mathrm{~min}$. The vein was emptied, and washed with HBS until the resulting $A_{280}$ reached $<0.005$ (5 $\mathrm{ml} / \mathrm{cm}$ ). The vessel was filled with HBS containing $10 \mathrm{mM}$ EACA (1 $\mathrm{ml} / \mathrm{cm}$ ), and incubated at $21^{\circ} \mathrm{C}, 10 \mathrm{~min}$. The EACA eluate was collected and concentrated 45-fold by ultrafiltration (Centricon-10 filter). Samples including the EACA eluate (lane 1), final HBS wash (lane 2), standard Lys-PLG (lane 3), and standard Glu-PLG (lane 4) were applied to a $7.5 \%$ nonreducing Laemmli gel, and processed as described in the legend to Fig. 5.

PLG (lane 2), the EACA eluate (lane 1) contained material which comigrated with both authentic Lys-PLG (lane 3) and authentic Glu-PLG (lane 4). The lower molecular mass, Lys-
PLG-like species represented $34.9 \pm 1.0 \%(\mathrm{SD}, n=3$ ) of the total recoverable labeled material by laser densitometry. This experiment suggests that endothelial cells in situ, like cultured HUVEC, possess the ability to convert Glu-PLG to the lower molecular mass form.

Since the serine protease plasmin is the major enzyme known to convert Glu-PLG to Lys-PLG (1-3), we examined the effect of various plasmin inhibitors on the ability of HUVEC to carry out this reaction. HUVEC, either in monolayer (Fig. $7 A$ and $C$ ) or in suspension (Fig. $7 B$ ), were incubated with ${ }^{125}$ I-Glu-PLG in the presence or absence of a variety of inhibitors. As shown in Fig. $7 \mathrm{~A}$, a variety of protease inhibitors including PAI (lane 3), the rapidly acting physiologic inhibitor of both urokinase-like and tissue-type plasminogen activators, $\alpha_{2}$-PI (lane 6), and the general serine protease inhibitors pancreatic trypsin inhibitor (lane 4) and D-phenylalanyl-L-prolyl-L-arginine chloromethylketone (PPACK) (lane 5), all failed to impede the formation of the lower molecular weight species (lane 7). In data not shown, phenylmethylsulfonyl fluoride also failed to inhibit this effect. Only DFP ( 2.5 $\mathrm{mM}$ ) (Fig. 7 C) blocked formation of the 87,000-kD form.
A

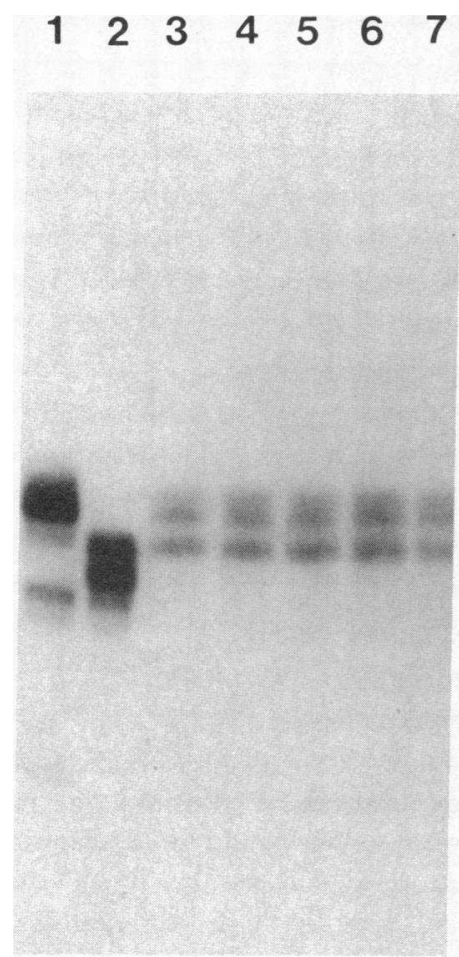

B

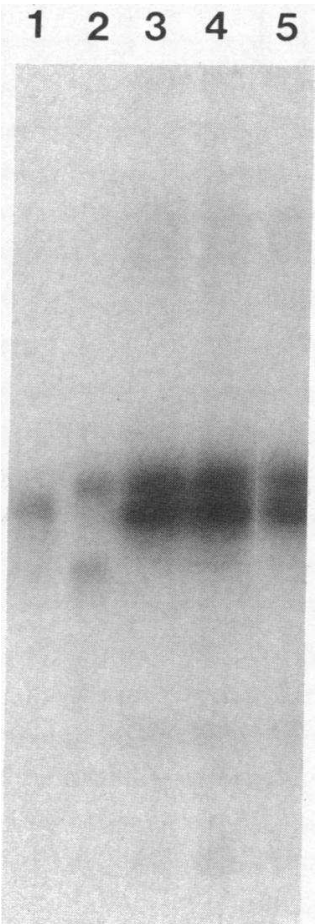

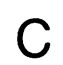

123

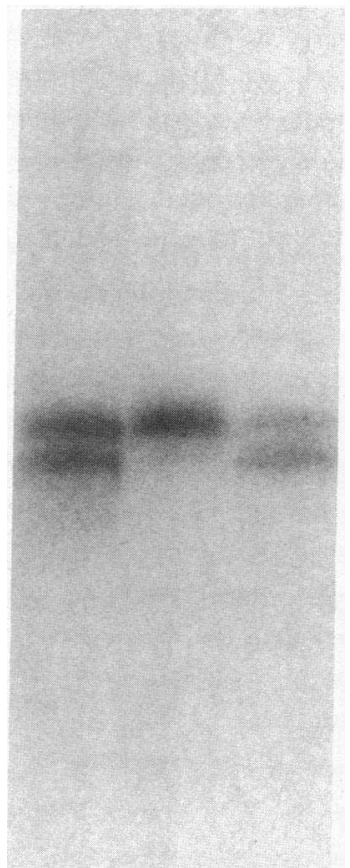

Figure 7. Effect of various protease inhibitors on ligand recovery. $(A)$ Serine protease inhibitors. HUVEC were prepared as described in the legend to Fig. 5, and incubated with ${ }^{125} \mathrm{I}-$ Glu-PLG (sp act 95,790 $\mathrm{cpm} / \mathrm{pmol} ; 5.4 \mu \mathrm{g} / \mathrm{well}$ ) in IB(5) (see Fig. 3 ), $30 \mathrm{~min}, 4^{\circ} \mathrm{C}$ in the presence of the following inhibitors: PAI-1 $0.44 \mathrm{nM}$ (lane 3), pancreatic trysin inhibitor $200 \mathrm{nM}$ (lane 4), PPACK $100 \mathrm{nM}$ (lane 5), $\alpha_{2}$-PI 80 nM (lane 6), or no inhibitor (lane 7). Cells were then washed three times with IB(5), and eluted with $\mathrm{IB}(5) / 10 \mathrm{mM}$ EACA. Cell surface eluates (lanes 3-7) as well as standard ${ }^{125}$ I-Glu-PLG (lane 1) or standard ${ }^{125}$ I-Lys-PLG (lane 2), were run on a $7.5 \%$ nonreducing SDS gel, fixed, dried, and exposed. A small amount of inactive plasmin was present in the authentic Glu-PLG sample (lane 1 , lower band). $(B)$ Calpain inhibitors. HUVEC in monolayer $\left(\sim 1 \times 10^{6}\right)$ were har- vested, resuspended in four aliquots $(0.25 \mathrm{ml})$, and incubated $21^{\circ} \mathrm{C}$, $30 \mathrm{~min}$ with ${ }^{125} \mathrm{I}-\mathrm{Glu}-\mathrm{PLG}(1.8 \mu \mathrm{g})$ alone (lane 5), or with ${ }^{125} \mathrm{I}-\mathrm{Glu}$ PLG in the presence of $1 \mathrm{mM}$ iodoacetic acid (lane 3), $1 \mathrm{mM}$ leupeptin (lane 4). Starting ${ }^{125} \mathrm{I}-\mathrm{L}$ ys-PLG and ${ }^{125} \mathrm{I}-\mathrm{Glu}-\mathrm{PLG}$ are shown in lanes 1 and 2, respectively. After incubation, HUVEC were centrifuged at $15,000 \mathrm{~g}, 5 \mathrm{~min}$, washed twice, and eluted with $\mathrm{IB}(5) / 10$ mM EACA ( $60 \mu \mathrm{l}$ per pellet). Samples for $9 \%$ SDS gels were processed as described in $A$. (C) DFP. Monolayers of HUVEC, prepared as in $A$, were incubated with ${ }^{125}$ I-Glu-PLG $(1.8 \mu \mathrm{g})$ in IB(5) alone (lane 1), in the presence of DFP (2.5 mM in 1\% 2-propanol/IB[5]) (lane 2), or in the presence of $\mathrm{IB}(5)$ containing 1\% 2-propanol alone (lane 3). HUVEC eluates were prepared as described in $A$, and run on $7.5 \%$ SDS gels. 
In controlling specialized cellular functions, calcium-activated proteases may be plasma membrane associated (17). We therefore tested "calpain" inhibitors in the same experiment (Fig. 7 B). Neither leupeptin (lane 3) nor iodoacetic acid (lane 4 ) demonstrated any effect on the appearance of the lower molecular mass form, demonstrating that sulfhydryl proteases were most likely not involved in the Glu-PLG to Lys-PLG conversion.

Identification of Lys-PLG on endothelial surface of intact blood vessels. Immunoblot analysis was utilized to identify forms of plasminogen elutable with EACA from intact human umbilical veins. As demonstrated in Fig. 8, PBS/EACA eluates (lane 5) from umbilical cord veins contained two molecular species migrating at $\sim 87,000$ and $\sim 85,000 \mathrm{kD}$, respectively, and comigrating with authentic ${ }^{125} \mathrm{I}-\mathrm{L}$ ys-PLG (lane 2). Both species reacted with monoclonal antibody to human Lys-PLG (LPm1). In additional experiments in which blots were developed with polyclonal antibody (not shown), a third band of 93,000 $\mathrm{kD}$ and representing, by densitometry, $15-29 \%$ of the total cross-reacting material was noted. The specificity of the monoclonal probe is further demonstrated in this experiment by the fact that it failed to react with either BSA ( $50 \mathrm{ng}$, lane 1 ) or with authentic Glu-PLG (50 ng, lane 3). Non-EACA eluates contained only a trace of immunoreactive material. It appears, therefore, that EACA eluates of umbilical cord veins clearly contained immunodetectable Lys-PLG which accounted for $\sim 71-85 \%$ of recoverable plasminogen species, the remainder representing Glu-PLG.

In addition, frozen sections of intact vessels from a variety of human tissues were evaluated immunohistochemically. Lys-PLG was detected on the surface of histologically normal human umbilical vein using the monoclonal antibody LPm 1 (Fig. $9 \mathrm{~A}$ ). The staining was localized to a rim on the endothelial cell surface. Similar but less intense staining was observed

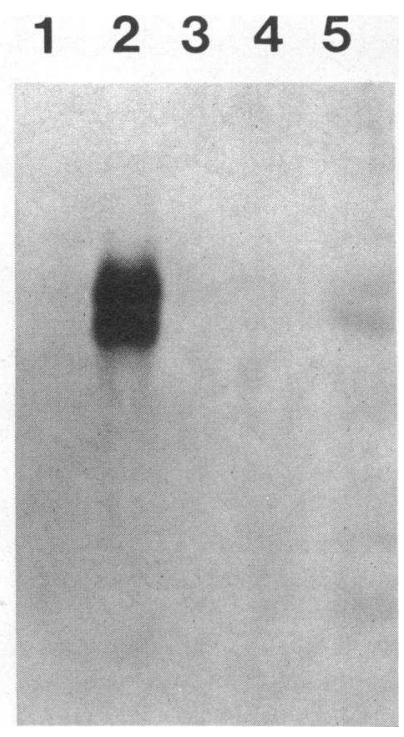

Figure 8. Identification of LysPLG eluted from intact umbilical veins using monoclonal LPm1. A $7.5 \%$ Laemmli SDS polyacrylamide gel was loaded with $50 \mathrm{ng}$ each of the following standard proteins: BSA, lane 1; authentic Lys-PLG, lane 2; authentic GluPLG, lane 3. Eluates were prepared from fresh $(<2$-h-old $)$ intact umbilical veins by washing the vessels at $4^{\circ} \mathrm{C}$ with PBS containing $2.5 \mathrm{mM} \mathrm{DFP}$, and $1 \mathrm{mM}$ PMSF (PBS/DFP/PMSF) until the $A_{280}$ of the washing buffer reached $0(\sim 10 \mathrm{ml} / \mathrm{cm}$ of cord length). Umbilical veins were then filled with PBS/DFP/PMSF ( 1 $\mathrm{ml} / \mathrm{cm}$ ) with or without $10 \mathrm{mM}$ EACA, and incubated at $4^{\circ} \mathrm{C}, 30$ min. Eluates were collected, concentrated (Amicon filters), and aliquots (90 $\mu \mathrm{g}$ of total protein per lane) applied to the gel (PBS eluate, lane 4; PBS/EACA eluate, lane 5). Resolved proteins were blotted onto transfer membranes which were then blocked, washed, and developed with monoclonal antibody directed against Lys-PLG (1:500), followed by alkaline phosphatase-conjugated goat anti-mouse immunoglobulin (1:500). on the endothelial cell surface of umbilical arteries. No staining was detected when the primary antibodies used were monoclonals to human $\lambda$ light chains, human prothrombin, or human albumin (not shown), or when monoclonal antibody LPm 1 was omitted (Fig. 9 B). Similar specific staining for Lys-PLG was detected in vessels in other tissues including renal glomeruli during rejection, inflamed tonsil, dermal capillaries from patients with active systemic lupus erythematosus, and normal brain (Fig. $10 A-D$ ), as well as other tissues. These results suggest that Lys-PLG may be a widespread component of the endothelial surface. Without benefit of a monoclonal antibody specific for Glu-PLG, it was impossible to determine whether this protein had a similar distribution on the endothelium. Results from polyclonal blotting experiments referred to above suggest that Glu-PLG may represent $15-29 \%$ of total elutable plasminogen on normal umbilical veins.

\section{Discussion}

This study demonstrates for the first time that the human endothelial cell surface has the capacity to convert the circulating, native form of plasminogen (Glu-PLG) to its modified, more activatable form (Lys-PLG). In addition, we have shown that cultured HUVEC can bind Lys-PLG with high affinity and in a saturable, reversible, and lysine-binding site-dependent fashion, and that Lys-PLG is a preferred ligand for a proportion of plasminogen-binding sites on the cell surface. Lys-PLG has also been demonstrated on the surface of endothelial cells in tissue sections stained with a specific monoclonal antibody (LPm1), and Lys-PLG was also recovered in EACA eluates from intact umbilical vessels. Thus, whereas Glu-PLG circulates in the plasma, Lys-PLG may represent a specialized, "preactivation" form of this zymogen which is confined to cell surfaces.

Historically, the role of preactivation intermediates in plasminogen activation has been controversial. Based on electrophoretic and circular dichroism analyses of activation of Glu-PLG in vitro, it was originally proposed that activation in vivo might involve the formation of $\mathrm{N}$-terminal lysyl or methionyl forms of the molecule $(1,18,19)$. More recently, however, with the availability of a Lys-PLG specific monoclonal antibody, neither Lys-PLG nor Lys-plasmin-antiplasmin complexes could be detected in the plasma of normal subjects, although three of seven patients undergoing thrombolytic therapy with tissue plasminogen activator had circulating Lysplasmin-antiplasmin (4). Our data suggest that formation of the preactivation intermediate Lys-PLG may be physiologic in a compartment confined to the vessel wall, and we hypothesize that an endothelial cell serine protease may mediate this event.

Previous studies have shown that human Glu-PLG, the native, circulating form, binds specifically and with high affinity to cultured HUVEC (9), at a site possibly related to cellsurface gangliosides (20). The present study now indicates by both ELISA (Fig. 1) and radioligand experiments (Fig. 3) that Lys-PLG also binds to these cells in a dose-dependent and saturable fashion. Binding reached a steady state at 20-30 min at which time $\sim 70 \%$ of binding, the same proportion inhibitable in the presence of the lysine analogue EACA, was reversible by "infinite dilution" of unbound ligand. Binding was therefore subject to a dynamic equilibrium, and thus suitable 

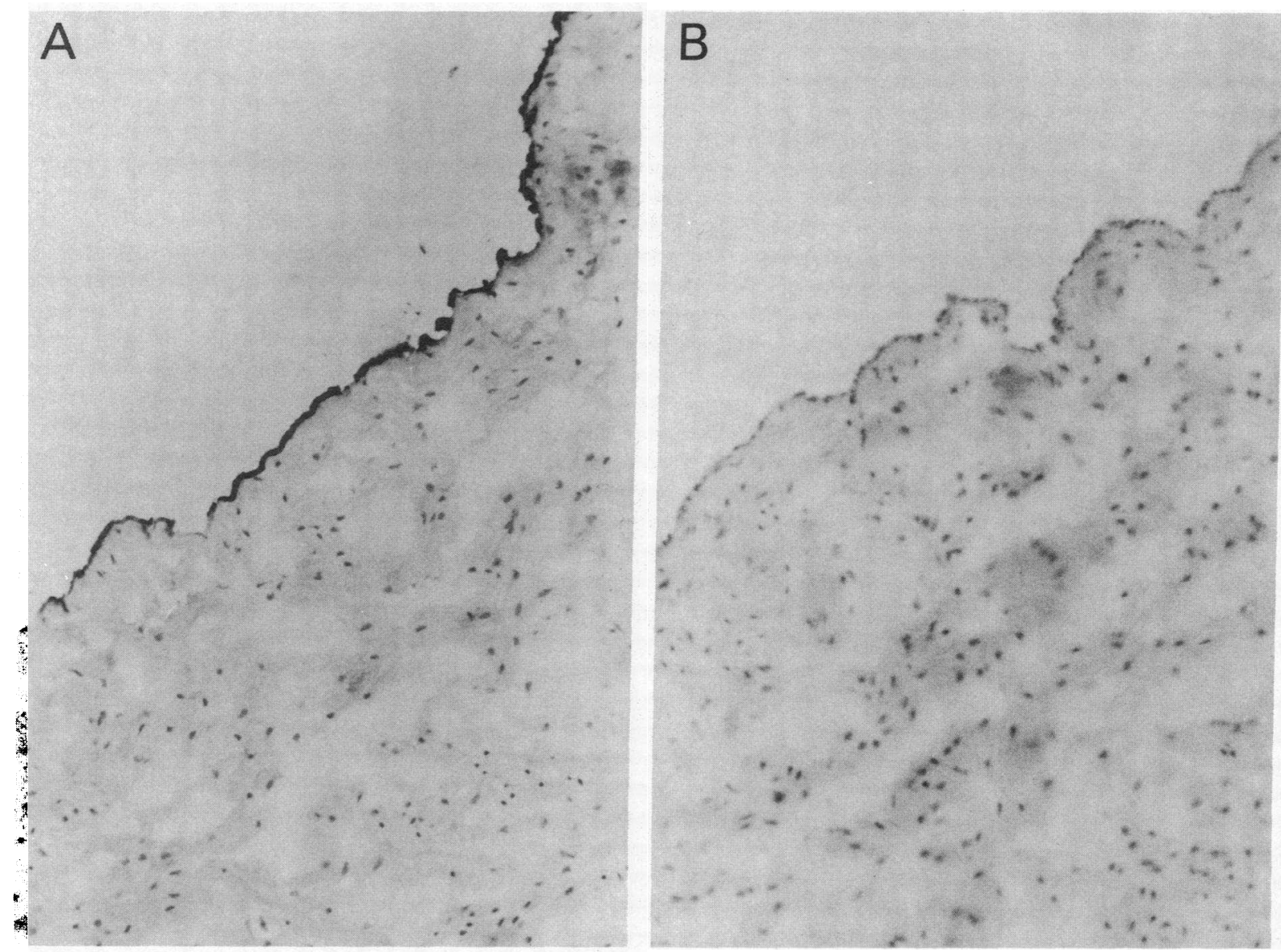

Figure 9. Immunohistochemical identification of Lys-PLG in frozen tissue sections of human umbilical cord veins using monoclonal LPm1. $(A)$ Dense staining of the endothelial surface. $(B)$ No primary antibody control. No staining is observed. $\times 530$.

for Scatchard analysis, which demonstrated the presence of two discrete saturable sites.

The present data indicate, furthermore, that Lys-PLG may represent a preferred ligand for a proportion of plasminogen binding sites on the cell surface. In cold competition studies, Lys-PLG proved to be a far better competitor of ${ }^{125}$ I-Lys-PLG binding than Glu-PLG (Fig. $4 \mathrm{~A}$ ). The $\mathrm{I}_{50}$ for Glu-PLG (48-fold excess) was $\sim 1 \frac{1 / 2}{2} \log$ orders higher than that for Lys-PLG (equimolar), suggesting much higher affinity of these sites for Lys-PLG as opposed to Glu-PLG. Lys-PLG was also at least as effective a competitor as Glu-PLG for ${ }^{125} \mathrm{I}-\mathrm{Glu}-\mathrm{PLG}$ binding sites with $I_{50}$ values suggesting a higher affinity for these sites (Fig. $4 \mathrm{~B}$ ). Formal binding data (Fig. 3) corroborate this finding since the dissociation constant for the major Lys-PLG site $(120 \mathrm{nM})$ is two- to threefold lower than that previously determined for Glu-PLG (310 nM) (9).

Our studies clearly demonstrate that cultured endothelial cells (Fig. 5) and endothelial cells in situ (Fig. 6) have the capacity to convert Glu-PLG to Lys-PLG. This effect was rapid and temperature dependent, suggesting a discrete catalytic event. Since the formation of Lys-PLG from Glu-PLG could be inhibited by the serine protease inhibitor DFP, we have postulated that this reaction is carried out by a serine protease with Lys-Lys specificity. Although plasmin remains a possible contender, we have been unable to inhibit the conversion with several agents known to inhibit fluid phase plas- min, including $\alpha_{2}$-PI, PPACK, and leupeptin (Fig. 7). Although plasmin associated with group A streptococci was insensitive to $\alpha_{2}$-PI, it was inhibited by aprotinin or PPACK (21). Similar active site protection from physiologic inhibitors has also been reported for sperm-associated ram seminal acro$\sin (22)$, macrophage-associated urokinase $(23,24)$, fibrin-associated plasmin (25), and HUVEC-bound tissue plasminogen activator (10), thus raising the question of whether a protected form of plasmin could be the catalytic agent.

Cell surface binding sites for fibrinolytic proteins are ubiquitous in nature $(26,27)$. Urokinase is found in association with fibroblasts $(28,29)$, the monocytoid cell line U937 (30, $31)$, the epidermoid cell line A431 $(32,33)$, mouse spermatozoa (34), and mouse erythroleukemia cells (35). Tissue plasminogen activator binds to HUVEC (10), and plasmin has been reported to bind to cultured mini-pig aortic endothelial cells (36), and has also been found by immunofluorescence on various tumor cells $(37,38)$. Glu-PLG interacts with platelets $(39,40)$, U937 cells and fibroblasts (41), and monocytes, granulocytes, and lymphocytes, but not erythrocytes (42). Plasminogen has also been found by immunofluorescence in association with capillary endothelium (37).

Nonfibrinolytic cell surface serine proteases may also serve to regulate specialized cellular functions in a variety of systems. Trypsinlike proteases present in rat liver plasma membranes (43) and human erythrocyte membranes (44) may be 

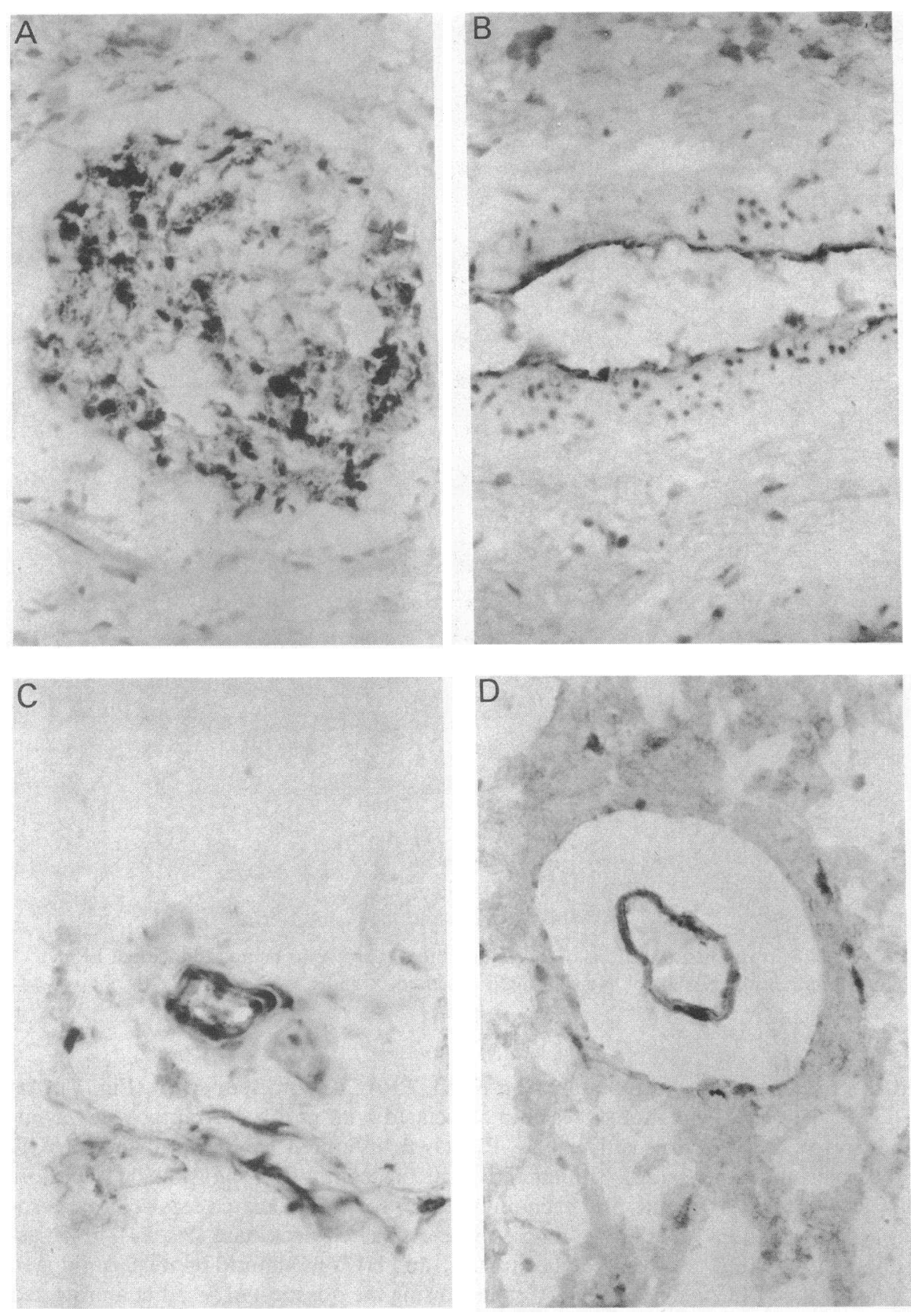

Figure 10. Immunohistochemical identification of Lys-PLG in frozen tissue sections using monoclonal antibody LPm $1 .(A)$ Glomerulus from chronically rejected kidney. $(B)$ Blood vessel in tonsillar capsule. $(C)$ Capillary in skin from patient with systemic lupus erythematosus. $(D)$ Blood vessel in biopsy specimen of normal brain. $\times 875$. involved in membrane processing. "Memsin" in plasma membranes of Walker 256 carcinosarcoma cells promotes their invasiveness (45). Membrane-bound acrosin on capacitated spermatozoa permits penetration of the zona pellucida during fertilization (22).

In addition to showing that HUVEC can convert Glu-PLG to a species that comigrates with Lys-PLG, we have also demonstrated Lys-PLG on the surface of intact umbilical veins and on the endothelium from vessels in a variety of tissues. Immunoblot analyses of EACA eluates from umbilical veins show a doublet that comigrates with authentic Lys-PLG (forms 1 and 2) and which reacts with a monoclonal antibody (LPm1) specific for Lys-PLG (Fig. 8). Similar experiments with polyclonal antibody showed a third cross-reacting band that comigrated with Glu-PLG, suggesting that a small per- centage (15-29\%) of elutable plasminogen exists in the Gluform as well. These data were corroborated by immunohistochemical studies which unequivically show Lys-PLG confined to the vascular endothelium in a variety of normal and inflamed tissues (Figs. 9 and 10). Relatively small amounts of Glu-PLG were also detected in umbilical cord eluates, but without benefit of a monoclonal antibody specific for GluPLG, we cannot yet delineate the exact tissue distribution of this form of the zymogen.

Taken together, these as well as previous (9) data support the hypothesis that HUVEC can bind circulating Glu-PLG and convert it to Lys-PLG by virtue of a serine protease present on the cell surface. Once Lys-PLG is formed, it appears to become a preferred ligand for plasminogen binding sites. Since Lys-PLG is the more activatable form of plasminogen, 
the net effect would be to enhance the fibrinolytic potential of the endothelial cell surface. Plasminogen activators, especially tissue plasminogen activator, also bind to the surface of HUVEC, retaining their catalytic activity (10). Since tissue plasminogen activator is synthesized and secreted by endothelial cells (46-48), local concentrations of tissue plasminogen activator may be sufficient to saturate high-affinity tissue plasminogen activator receptors and perhaps lower-affinity receptors as well. Thus, the potential to generate catalytic quantities of plasmin, would exist. Plasmin could then serve a dual role, promoting formation of Lys-PLG as binding occurs, and guarding against vessel occlusion during thrombogenic states. Such a mechanism would be even more important during inflammatory states where thrombosis is a frequent event. A similar mechanism might also apply in extravascular systems since recent data from this laboratory demonstrate binding and activation of Lys-PLG on macrophages (49). The endothelium, thus, by virtue of its immense surface area (50), represents a vast reservoir of localized fibrinolytic proteins, and the assembly of these proteins on the cell surface most likely provides a key protective mechanism against abnormal clotting.

\section{Acknowledgments}

We thank Ms. Nancy Hamel and Ms. Barbara Ferris for expert technical assistance.

Dr. Hajjar is the recipient of Clinical Investigator Award KO8 HL-01352 from the National Institutes of Health, and an Andrew W. Mellon Foundation Teacher-Scientist Award. This work was also supported in part by grant HL-18828 (Specialized Center of Research in Thrombosis) from the National Institutes of Health, and SO7 RR05396, awarded by the Biomedical Research Support Grant Program, Division of Research Resources, National Institutes of Health.

\section{References}

1. Wallen, P., and B. Wiman. 1975. On the generation of intermediate plasminogen and its significance for activation. In Proteases and Biologic Control. E. Reich, D. B. Rifkin, and E. Shaw, editors. Cold Spring Harbor Laboratory, Cold Spring Harbor, NY. 291-303.

2. Castellino, F. J. 1984. Biochemistry of human plasminogen. Semin. Thromb. Hemostasis. 10:18-23.

3. Lijnen, H. R., and D. Collen. 1982. Interaction of plasminogen activators and inhibitors with plasminogen and fibrin. Semin. Thromb. Hemostasis. 8:2-10.

4. Holvoet, P., H. R. Lijnen, and D. Collen. 1985. A monoclonal antibody specific for lys-plasminogen: application to the study of the activation pathways of plasminogen in vivo. J. Biol. Chem. 260:12106-12111.

5. Lucas, M. A., L. J. Fretto, and P. A. McKee. 1983. The binding of human plasminogen to fibrin and fibrinogen. J. Biol. Chem. 258:4249-4256.

6. Hoylaerts, M., D. C. Rijken, H. R. Lijnen, and D. Collen. 1982. Kinetics of the activation of plasminogen by human tissue plasminogen activator: role of fibrin. J. Biol. Chem. 257:2912-2919.

7. Markus, G., J. L. Evers, and G. H. Hobika. 1978. Comparison of some properties of native (glu) and modified (lys) human plasminogen. J. Biol. Chem. 253:733-739.

8. Markus, G., R. L. Priore, and F. C. Wissler. 1979. The binding of tranexamic acid to native (glu) and modified (lys) human plasminogen and its effect on conformation. J. Biol. Chem. 254:1211-1216.

9. Hajjar, K. A., P. C. Harpel, E. A. Jaffe, and R. L. Nachman. 1986. Binding of plasminogen to cultured human endothelial cells. $J$. Biol. Chem. 261:11656-11662.

10. Hajjar, K. A., N. M. Hamel, P. C. Harpel, and R. L. Nachman.
1987. Binding of tissue plasminogen activator to cultured human endothelial cells. J. Clin. Invest. 80:1712-1719.

11. Martin, B. M., W. W. Wasiewski, J. W. Fenton, and T. C. Detwiler. 1976. Equilibrium binding of thrombin to platelets. Biochemistry. 15:4886-4893.

12. Munson, P. J., and D. Rodbard. 1980. Ligand: a versatile computerized approach for characterization of ligand binding systems. Anal. Biochem. 107:220-239.

13. Laemmli, U. K. 1970. Cleavage of structural proteins during the assembly of the head of bacteriophage T4. Nature (Lond.). 227:680-684.

14. Daniel, T. O., W. J. Schneider, J. L. Goldstein, and M. S. Brown. 1983. Visualization of lipoprotein receptors by ligand blotting. J. Biol. Chem. 258:4606-4611.

15. Beisiegel, U., W. J. Schneider, M. S. Brown, and J. L. Goldstein. 1982. Immunoblot analysis of low density lipoprotein receptors in fibroblasts from subjects with familial hypercholesterolemia. J. Biol. Chem. 257:13150-13156.

16. Turner, B. M. 1986. Use of alkaline phosphatase-conjugated antibodies for detection of protein antigens on nitrocellulose filters. Methods Enzymol. 121:848-855.

17. Mellgren, R. L. 1987. Calcium-dependent proteases: an enzyme system active at cellular membranes? FASEB (Fed. Am. Soc. Exp. Biol.) J. 1:110-115.

18. Wiman, B., and P. Wallen. 1973. Activation of human plasminogen by an insoluble derivative of urokinase: structural changes of plasminogen in the course of activation to plasmin and demonstration of a possible intermediate compound. Eur. J. Biochem. 36:25-31.

19. Sjoholm, I., B. Wiman, and P. Wallen. 1973. Studies on the conformational changes of plasminogen induced during activation to plasmin and by 6-aminohexanoic acid. Eur. J. Biochem. 39:471-479.

20. Miles, L. A. and E. F. Plow. 1987. Cellular urokinase receptors: influence of gangliosides. Blood. 70:406A. (Abstr.)

21. Lottenberg, R., C. C. Broder, and M. D. P. Boyle. 1987. Identification of a specific receptor for plasmin on a group A streptococcus. Infect. Immun. 55:1914-1918.

22. Brown, C. R., and E. F. Hartree. 1976. Effects of acrosin inhibitor on the soluble and membrane-bound forms of ram acrosin, and a reappraisal of the role of the enzyme in fertilization. Hoppe-Seyler's $Z$. Physiol. Chem. 357:57-65.

23. Chapman, H. A., Z. Vavrin, and J. B. Hibbs. 1982. Macrophage fibrinolytic activity: identification of two pathways of plasmin formation by intact cells and of a plasminogen activator inhibitor. Cell. 28:653-662.

24. Chapman, H. A., O. L. Stone, and Z. Vavrin. 1984. Degradation of fibrin and elastin by intact human alveolar macrophages in vitro. J. Clin. Invest. 73:806-815.

25. Wiman, B., and D. Collen. 1978. Molecular mechanisms of physiologic fibrinolysis. Nature (Lond.). 272:549-550.

26. Miles, L. A., and E. F. Plow. 1988. Plasminogen receptors: ubiquitous sites for cellular regulation in fibrinolysis. Fibrinolysis. 2:61-71.

27. Blasi, F. 1988. Surface receptors for urokinase plasminogen activator. Fibrinolysis. 2:73-84.

28. DelRosso, M., G. Dini, and G. Fibbi. 1985. Receptors for plasminogen activator, urokinase, in normal and Rous sarcoma virustransformed mouse fibroblasts. Cancer Res. 45:630-636.

29. Fibbi, G., G. Dini, F. Pasquali, M. Pucci, and M. DelRosso. 1986. The $M_{\mathrm{r}} 17,500$ region of the A chain of urokinase is required for interaction with a specific receptor in A431 cells. Biochim. Biophys. Acta. 885:301-308.

30. Vassalli, J.-D., D. Baccino, and D. Belin. 1985. A cellular binding site for the $M_{\mathrm{r}} 55,000$ form of the human plasminogen activator, urokinase. J. Cell Biol. 100:86-92.

31. Stoppelli, M. P., A. Corti, A. Soffientini, G. Cassani, F. Blasi, and R. K. Assoian. 1985. Differentiation-enhanced binding of the amino-terminal fragment of human urokinase plasminogen activator 
to a specific receptor on U937 monocytes. Proc. Natl. Acad. Sci. USA. 82:4939-4943.

32. Stoppelli, M. P., C. Tacchetti, M. V. Cubellis, A. Corti, V. J. Hearing, G. Cassani, E. Appella, and F. Blasi. 1986. Autocrine saturation of pro-urokinase receptors on human A431 cells. Cell. 45:675684.

33. Gross, J. L., M. N. Krupp, D. B. Rifkin, and M. D. Lane. 1983. Down-regulation of epidermal growth factor receptor correlates with plasminogen activator activity in human A431 epidermoid carcinoma cells. Proc. Natl. Acad. Sci. USA. 80:2276-2280.

34. Huarte, J., D. Belin, D. Bosco, A.-P. Sappino, and J.-D. Vassalli. 1987. Plasminogen activator and mouse spermatozoa: urokinase synthesis in the male genital tract and binding of the enzyme to the sperm cell.surface. J. Cell Biol. 104:1281-1289.

35. DelRosso, M., M. Pucci, G. Fibbi, and G. Dini. 1987. Interaction of urokinase with specific receptors abolishes the time of commitment to terminal differentiation of murine erythroleukaemia (Friend) cells. Br. J. Haematol. 66:289-294.

36. Bauer, P. I., R. Machovich, K. G. Buki, E. Csonka, S. A. Koch, and I. Horvath. 1984. Interaction of plasmin with endothelial cells. Biochem. J. 218:119-124.

37. Burtin, P., G. Chavanel, J. Andre. 1985. The plasmin system in human colonic tumors: an immunofluorescence study. Int. J. Cancer. 35:307-314.

38. Burtin, P., G. Chavanel, J. Andre-Bourgaran, and A. Gentile. 1987. The plasmin system in human adenocarcinomas and their metastases: a comparative immunofluorescence study. Int. J. Cancer. 39:170-178.

39. Miles, L. A., and E. F. Plow. 1985. Binding and activation of plasminogen on the platelet surface. J. Biol. Chem. 260:4303-4311.

40. Miles, L. A., M. H. Ginsberg, J. G. White, and E. F. Plow. 1986. Plasminogen interacts with human platelets through two distinct mechanisms. J. Clin. Invest. 77:2001-2009.
41. Plow, E. F., D. E. Freaney, J. Plescia, and L. A. Miles. 1986. Evidence for plasminogen and urokinase receptors on the same cell type. J. Cell Biol. 103:2411-2420.

42. Miles, L. A., and E. F. Plow. 1987. Receptor mediated binding of the fibrinolytic components, plasminogen and urokinase, to peripheral blood cells. Thromb. Haemostasis. 58:936-942.

43. Tanaka, K., T. Nakamura, and A. Ichihara. 1986. A unique trypsin-like protease associated with plasma membranes of rat liver. $J$. Biol. Chem. 261:2610-2615.

44. Golovtchenko-Matsumoto, A., I. Matsumoto, and T. Osawa. 1982. Degradation of band-3 glycoprotein in vitro by a protease isolated from human erythrocyte membranes. Eur. J. Biochem. 121:403-407.

45. LaBombardi, V. J., E. Shaw, J. F. DiStefano, G. Beck, F. Brown, and S. Zucker. 1983. Isolation and characterization of a trypsin-like serine protease from the membranes of Walker 256 carcinosarcoma cells. Biochem. J. 211:695-700.

46. Loskutoff, D. J., and T. S. Edgington. 1977. Synthesis of a fibrinolytic activator and inhibitor by endothelial cells. Proc. Natl. Acad. Sci. USA. 74:3903-3907.

47. Levin, E. G., and D. J. Loskutoff. 1982. Cultured bovine endothelial cells produce both urokinase and tissue-type plasminogen activators. J. Cell Biol. 94:631-636.

48. Booyse, F. M., G. Usikowicz, S. Feder, and J. Scheinbuks. 1984. Isolation and characterization of a urokinase-type plasminogen activator $\left(M_{\mathrm{r}} 54,000\right)$ from cultured endothelial cells indistinguishable from urinary urokinase. J. Biol. Chem. 259:7198-7205.

49. Silverstein, R. S., R. J. Friedlander, R. J. Nicholas, and R. L. Nachman. 1988. Binding, localization, and activation of lys-plasminogen on macrophage cell surfaces. J. Clin. Invest. In press.

50. Smaje, L., B. W. Zweifach, and M. Intaglietta. 1970. Micropressures and capillary filtration coefficients in single vessels of the cremaster muscle of the rat. Microvasc. Res. 2:96-110. 